\title{
Initiation of Cracks in Dental Amalgam
}

\author{
OSAMA YOUNIS,* KAMAL ASGAR, and JOHN M. POWERS \\ School of Dentistry, University of Michigan, Ann Arbor, Michigan 48104, USA
}

The force required to initiate cracks in dental amalgam beams was measured and related to the microstructure. The force measured was dependent on age and on the distribution of phases on the tension side of the beam. The Ag-Cu phase is most resistant to failure in Dispersalloy and an experi. mental alloy.

During the past 12 years, several amalgam alloys have been developed and are commercially available. Spherical alloys and Dispersalloy $^{\mathrm{a}}$ are two examples of the new alloys that have been developed.

In 1965, Asgar and Sutfin ${ }^{1}$ developed a technique for studying the relationship of crack initiation to the microstructure of dental amalgam. According to their results, the path of cracks induced by bending stresses goes through voids and the $\gamma_{2}$ phase, then

Based on a thesis submitted in partial fulfilment of the MS degree in dental materials.

This investigation was supported by Grant No. DE00181 from the National Institutes of Health, Bethesda, Md.

Presented at the 52nd general session of the IADR in Atlanta, Ga, March 1974

Received for publication April 4, 1975.

Accepted for publication June 27, 1975.

- Present address: College of Dentistry, Dental Auxil. iary Research Institute, University of Tennessee, Mem. phis, Tenn.

- Lot no. 04938, Johnson \& Johnson, Dental Products Co., East Windsor, NJ. through the grain boundaries of the $\gamma_{1}$ phase, then around the $\gamma$ phase, and then through the $\gamma$ phase. However, they did not study the magnitude of force needed to initiate and propagate a crack.

The study reported here was undertaken not only to determine the force needed to initiate and propagate a crack in dental amalgam but also to study the initiation and propagation of cracks in Dispersalloy and spherical amalgam alloys.

\section{Materials and Methods}

Three commercial dental amalgam alloys and one experimental alloy were triturated in mechanical amalgamators. Alloy-mercury ratios and trituration times used are shown in Table 1.

The triturated amalgam was packed with a $1-\mathrm{mm}$ diameter plugger in a three-piece steel die with the dimensions of $0.06 \times 0.06$ $\times 1.06$ inches. $^{1}$ The amalgam beam was allowed to set for 15 minutes before being removed. A total of ten beams were prepared from each alloy. Five beams were tested after two days and the remainder after four months. All the specimens were kept in an incubator at $37 \mathrm{C}$ for the aforementioned periods. After the assigned period, amalgam beams were embedded in a cold-

TABLE 1

alloy-Mercury Ratio and Trituration Time

\begin{tabular}{lcccc}
\hline \multicolumn{1}{c}{ Alloy } & $\begin{array}{c}\text { No. of } \\
\text { Specimens }\end{array}$ & $\begin{array}{c}\text { Hg/Alloy } \\
\text { Ratio (\%) }\end{array}$ & $\begin{array}{c}\text { Trituration } \\
\text { Time (sec) }\end{array}$ & $\begin{array}{c}\text { Amalgamator } \\
\text { Used }\end{array}$ \\
\hline Optaloy & 10 & 54 & 12 & Capmaster* \\
Spher-A-Cap & 10 & 48 & 15 & Capmaster \\
Dispersalloy & 10 & 50 & 10 & Capmaster \\
Experimental alloyt & 10 & 50 & 15 & Mc Shirley $\ddagger$ \\
\hline
\end{tabular}

- S. S. White Dental Manufacturing Co., Philadelphia, Pa.

+ All spherical alloys were composed of the following: Ag-Cu spherical particle: Ag, $72 \%$, $\mathrm{Cu}, 28 \% ; \mathrm{Ag}_{3} \mathrm{Sn}$ spherical particle: $\mathrm{Ag}, 70 \% \mathrm{Sn}, 27.5 \%$; and $\mathrm{Cu} 2.5 \%$ proportioned at one third $\mathrm{Ag}-\mathrm{Cu}$ to two thirds $\mathrm{Ag}-\mathrm{Sn}$.

$\ddagger$ Kerr Manufacturing Co., Romulus, Mich. 
curing plastic. ${ }^{b}$ The amalgam beams embedded in the plastic, hereafter called the composite beams, were polished for microstructural studies, following the procedure described by Allen, Asgar, and Peyton. ${ }^{2}$

The strain gauges ${ }^{c}$ were cemented on the indentor of the Flinn Strain Viewerd (Fig 1). The strain gauges were connected to a strain gauge amplifier. The strain gauges were then calibrated using a testing machine.e Detailed specimen preparation and testing procedure are given elsewhere ${ }^{3}$

Specimens were then studied microscopically. The force needed to initiate the crack was determined. Specimens were etched with iodide etch. ${ }^{2}$ The force data were treated statistically using the one- and two-way anallysis of variance. ${ }^{4}$ The Scheffe test was used

b Fibre Glass-Evercoat Co., Inc., Cincinnati, Ohio.

c $120.0 \pm 0.4 \%$ resistance in ohms, Micro-Measurements Co., Romulus, Mich.

d Dietert, Detroit, Mich.

- Universal Testing Instruments, Model TT-B, Instron Corp., Canton, Mass.

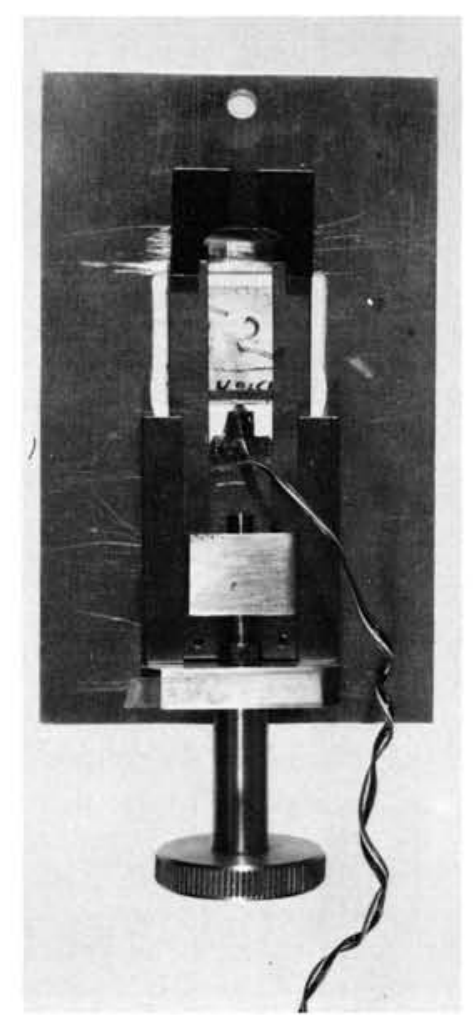

FIG 1.-Flinn Strain-Viewer with strain gauges cemented to indentor.
TABLE 2

Force Data OBTAined For TWO-DAy- AND FOUR-MONTH-OLD SPECIMENS

\begin{tabular}{lrl}
\hline \hline & \multicolumn{2}{c}{ Force (kg) } \\
\cline { 2 - 3 } Alloy Used & 2 Days & $4 \mathrm{Mo}$ \\
\hline Optaloy & $8.8 \dagger$ & $36.8 \dagger$ \\
$2.2 \mathrm{~cm}^{\bullet}$ & $(1.2)$ & $(1.2)$ \\
Spher-A-Cap & $14.1 \dagger$ & $34.2 \dagger$ \\
$2.2 \mathrm{~cm}^{\bullet}$ & $(0.7)$ & $(3.3)$ \\
Dispersalloy & $11.1 \ddagger$ & 17.9 \\
$2.1-1.7$ in & $(1.8)$ & $(1.4)$ \\
Experimental alloy & $15.5 \ddagger$ & 18.2 \\
$2.1-1.8 \mathrm{~cm}^{*}$ & $(2.5)$ & $(1.3)$ \\
\hline
\end{tabular}

- Width of composite beam

+ Statistically significant at the $95 \%$ confidence level using the two-way analysis of variance.

I Statistically significant at the $95 \%$ confidence level using the one-way analysis of variance. SD in parentheses; $\mathrm{N}=5$ in all cases.

for making comparisons among the means. ${ }^{4}$ Photomicrographs were taken with the scanning electron microscope. ${ }^{f}$

\section{Results}

The force data obtained for two-day and four-month specimens are summarized in Table 2. Values for Optaloyg and Spher-A$\mathrm{Cap}^{\mathrm{h}}$ both for two-day- and four-month-old specimens were different statistically as determined by two-way analysis of variance. A difference between means of $2.0 \mathrm{~kg}$ as calculated by the Scheffe method was needed to show a statistically significant effect. Values for Dispersalloy and the experimental alloy (two-day-old specimens) were statistically different as determined by one-way analysis of variance at the $95 \%$ confidence level. The values for Dispersalloy and the experimental alloy (four-month-old specimens) were not compared because of the differences in beam widths.

The phases through which the crack was initiated and propagated together with the possible choices among the phases on the tension side of the beam are summarized and presented as frequency data in Table 3.

\section{Discussion}

Theoretical beam width is influenced in part by the strength and modulus of elasticity

' Model TSM-U3, Japan Electron Optics Laboratory Co., LTD, Japan.

g Lot no. 1264-601602, L. D. Caulk Co., Milford, Del.

${ }^{\text {h }}$ Lot no. 1028, Kerr Manufacturing Co., Romulus. Mich. 
TABLE 3

FrequeNCY OF CRACK INITIATION IN TWO-DAY- AND FOUR-MONTH-OLD SPECIMENS

\begin{tabular}{|c|c|c|c|c|c|c|}
\hline \multirow[b]{2}{*}{ Optaloy, 2 days } & \multirow{2}{*}{$\begin{array}{c}\text { Frequency } \\
2 \\
3 \\
1\end{array}$} & \multicolumn{3}{|c|}{$\begin{array}{l}\text { Possible Phases } \\
\text { for Crack } \\
\text { Initiation }\end{array}$} & \multicolumn{2}{|c|}{$\begin{array}{l}\text { Phases Picked } \\
\text { by the Crack }\end{array}$} \\
\hline & & $\begin{array}{l}\gamma ; \\
\gamma ; \\
\mathrm{v} ;\end{array}$ & $\begin{array}{l}\gamma_{1} \\
\gamma_{1} \\
\gamma_{1}\end{array}$ & $\begin{array}{l}\gamma_{2} \\
\gamma_{2}\end{array}$ & $\begin{array}{l}\gamma_{1} \\
\gamma_{1}(1) \\
\mathbf{v}\end{array}$ & $\gamma_{2}(2)$ \\
\hline Optaloy, 4 mo & $\begin{array}{l}2 \\
3 \\
1\end{array}$ & $\begin{array}{l}\gamma ; \\
\gamma ;\end{array}$ & $\begin{array}{l}\gamma_{1} \\
\gamma_{1} \\
\gamma_{1}\end{array}$ & $\begin{array}{l}\gamma_{2} \\
\gamma_{2}\end{array}$ & $\begin{array}{l}\gamma_{1} \\
\gamma_{1}(1)\end{array}$ & $\begin{array}{l}\gamma_{2}(2) \\
\gamma_{2}\end{array}$ \\
\hline Spher-A-Cap, 2 days & $\begin{array}{l}3 \\
1 \\
1 \\
1\end{array}$ & $\begin{array}{l}\gamma \\
\gamma \\
\gamma\end{array}$ & $\begin{array}{l}\gamma_{1} \\
\gamma_{1} \\
\gamma_{1}\end{array}$ & $\begin{array}{l}\gamma_{2} \\
\gamma_{2} \\
\gamma_{2}\end{array}$ & $\begin{array}{l}\gamma_{1}(1) \\
\gamma_{1}\end{array}$ & $\begin{array}{l}\gamma_{2}(2) \\
\gamma_{2} \\
\gamma_{2}\end{array}$ \\
\hline Spher-A-Cap, 4 mo & $\begin{array}{l}2 \\
2 \\
1\end{array}$ & $\begin{array}{l}\gamma \\
\gamma \\
\gamma\end{array}$ & $\begin{array}{l}\gamma_{1} \\
\gamma_{1}\end{array}$ & $\begin{array}{l}\gamma_{2} \\
\gamma_{2}\end{array}$ & $\gamma_{\mathbf{1}}$ & $\begin{array}{l}\gamma_{2} \\
\gamma_{2}\end{array}$ \\
\hline $\begin{array}{l}\text { Commercial dispersed } \\
\text { alloy, } 2 \text { days }\end{array}$ & $\begin{array}{l}2 \\
1 \\
1 \\
1\end{array}$ & $\begin{array}{l}y ; \\
\gamma\end{array}$ & $\begin{array}{l}y_{1} \\
\gamma_{1} \\
\gamma_{1} \\
y_{1}\end{array}$ & $\begin{array}{l}\mathbf{E} \\
\mathbf{E}\end{array}$ & $\begin{array}{l}\gamma_{1} \\
\gamma_{1} \\
\gamma_{1} \\
\gamma_{1}\end{array}$ & \\
\hline $\begin{array}{l}\text { Commercial dispersed } \\
\text { alloy, } 4 \mathrm{mo}\end{array}$ & $\begin{array}{l}2 \\
1 \\
2\end{array}$ & $\begin{array}{l}\gamma ; \\
\gamma ;\end{array}$ & $\begin{array}{l}\gamma_{1} \\
\gamma_{1} \\
\gamma_{1}\end{array}$ & $\begin{array}{l}\mathbf{E} \\
\mathbf{E}\end{array}$ & $\begin{array}{l}\gamma_{1} \\
\gamma_{1} \\
\gamma_{1}\end{array}$ & \\
\hline $\begin{array}{l}\text { All-Spherical dispersed } \\
\text { alloy, } 2 \text { days }\end{array}$ & $\begin{array}{l}3 \\
1 \\
1\end{array}$ & $\begin{array}{l}\gamma ; \\
\gamma ;\end{array}$ & $\begin{array}{l}\gamma_{1} \\
\gamma_{1}\end{array}$ & $\begin{array}{l}\mathbf{E} \\
\mathbf{E} \\
\mathbf{E}\end{array}$ & $\begin{array}{l}\gamma_{1} \\
\gamma_{1} \\
\gamma\end{array}$ & \\
\hline $\begin{array}{l}\text { All-Spherical dispersed } \\
\text { alloy, } 4 \text { mo }\end{array}$ & $\begin{array}{l}3 \\
1 \\
1\end{array}$ & $\begin{array}{l}\gamma ; \\
\gamma ;\end{array}$ & $\begin{array}{l}\gamma_{1} \\
\gamma_{1} \\
\gamma_{1}\end{array}$ & $\begin{array}{l}\mathbf{E} \\
\mathbf{E}\end{array}$ & $\begin{array}{l}\gamma_{1} \\
\gamma_{1} \\
\gamma_{1}\end{array}$ & \\
\hline
\end{tabular}

Note: $\gamma$ represents the unreacted Ag-Sn phase; $\gamma_{1}$, Ag-Hg phase; $\gamma_{2}$, Sn-Hg phase; $v$, void; and $\mathrm{E}, \mathrm{Ag}-\mathrm{Cu}$ eutectic phase.

of the amalgam. Since the strength and modulus of elasticity of Dispersalloy and the experimental alloy change with time, the width of the beam required to initiate a stable crack is also time dependent. The increase in mechanical properties of these two alloys is because of elimination of the $\gamma_{2}$ phase. $^{5-7}$

The force data show that the Optaloy and Spher-A-Cap beams need more force to initiate a crack as the beam ages and suggest that either the strength of the amalgam is improved with time or the elastic modulus of the amalgam changes with time, either of which may have been caused by some changes in the microstructure of the amalgam. Differences in the microstructure between the two-day- and four-month-old specimens were not obvious from the photomicrographs. These microstructural changes might be manifested as a decrease in the weaker phase.

Crack initiation in Optaloy and Spher-ACap differed greatly depending on the phases present on the tension side of the amalgam beam. From Table 3, it was observed that in every instance where the three phases $(\gamma$, $\gamma_{1}$ and $\gamma_{2}$ ) were represented, the crack initiated in the $\gamma_{2}$ phase. The distribution of the various phases in the set dental amalgam varies greatly. The largest percentage of set amalgam mass consists of $\gamma_{1}$ and $\gamma$ phases, whereas the contribution of $\gamma_{2}$ phase is rather small.8,9 The probability of having $\gamma_{1}$ phase in the tension side of the amalgam beam is higher than obtaining $\gamma_{2}$ phase. The initiation of the crack in Optaloy and 


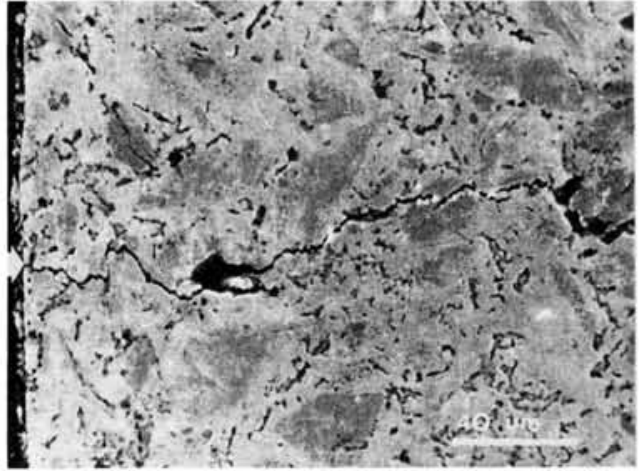
FIG 2.-Photomicrographs of Optaloy (left) and Spher-A-Cap (right). Arrows indicate
initiation of cracks. Note $90^{\circ}$ change in direction of crack near initiation of crack (Optaloy) On Spher-A-Cap also crack bypassed $\gamma$ particle near initiation of crack but later went through it.

Spher-A-Cap is shown in Figure 2. In some samples, two cracks initiated, one in the $\gamma_{1}$ phase and the other in the $\gamma_{2}$ phase. The crack that was initiated in the $\gamma_{2}$ phase was stopped from further propagation when it encountered a $\gamma$ particle. This suggests that $\gamma$ particle is a strong phase and that although the $\gamma_{2}$ phase is weaker than the $\gamma_{1}$ phase, this difference in strength between them may not be great.

In Dispersalloy and the experimental alloy there are two unreacted particles, $\mathrm{Ag}$-Sn particles and $\mathrm{Ag}-\mathrm{Cu}$ particles. A Sn-Cu phase (also known as the reaction ring) formed around the Ag-Cu particle. The matrix consisted of the Ag- $\mathrm{Hg}$ phase $\left(\gamma_{1}\right)$ and some microporosities. The same phases were observed in the experimental alloy. The main difference between their microstruc-

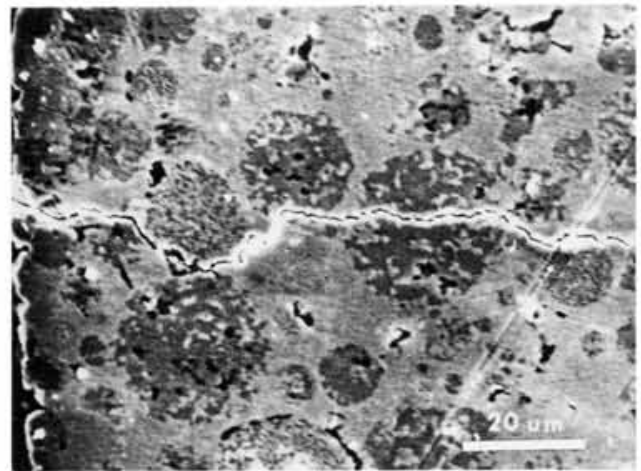

and Spher-A-Cap (right). Arrows indicate on of crack near initiation of crack (Optaloy).
ear initiation of crack but later went through it.

tures was that $\mathrm{Ag}-\mathrm{Sn}$ particles in the experimental alloy were spherical in shape (Fig 3).

In Dispersalloy and the experimental alloy, the crack initiated in the Ag- $\mathrm{Hg}$ phase in all of the samples except one where the crack initiated through the $\mathrm{Ag}-\mathrm{Sn}$ phase because this was the only choice. This suggests that the $\mathrm{Ag}$-Cu phase is more resistant to failure than the Ag-Sn phase. As the crack mostly initiated in the $\mathrm{Ag}-\mathrm{Hg}$ phase regardless of the phases represented on the tension side of the amalgam beam, this may indicate that the difference in strength between the $\gamma, \mathrm{Ag}$ $\mathrm{Cu}, \mathrm{Sn}-\mathrm{Cu}$, and $\mathrm{Ag}-\mathrm{Hg}$ phases are great, with the $\mathrm{Ag} \cdot \mathrm{Hg}$ phase being the weakest.

\section{Conclusions}

The phases through which a crack initiates is dependent on the distribution of the
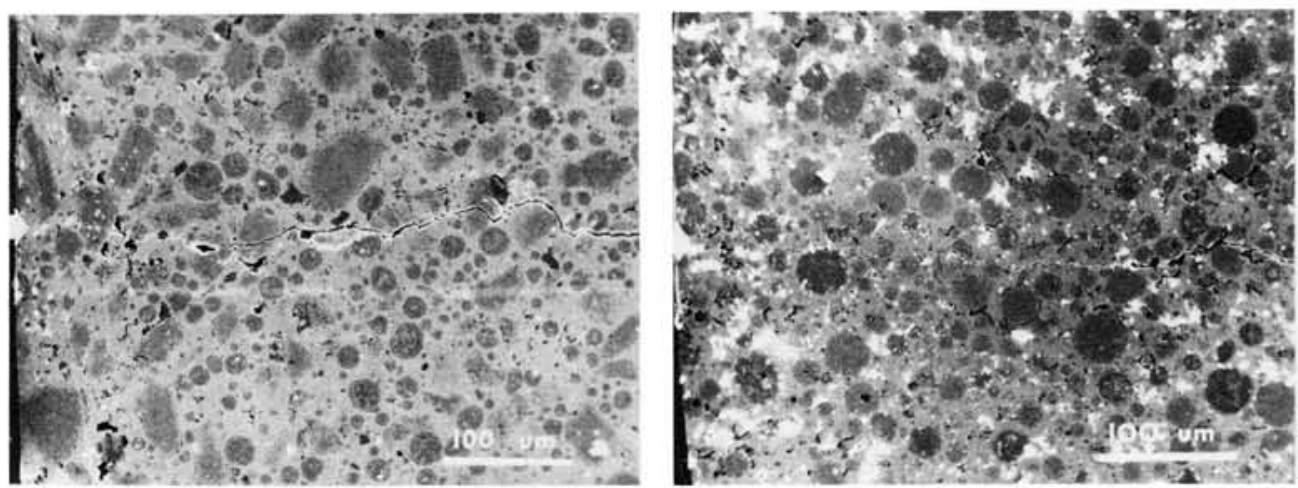

FIG 3.-Photomicrograph of Dispersalloy (left) and experimental alloy (right). Arrows indicate initiation of cracks. 
phases on the tension side of the amalgam beam.

The unreacted Ag-Sn phase is the most resistant to failure in Optaloy and Spher-ACap.

The Ag-Cu phase is the most resistant to failure in Dispersalloy and the experimental alloy.

The amount of force necessary to initiate a crack in all the dental amalgam alloys studied was dependent on the age of the amalgam.

\section{References}

1. Asgar, K., and SUTfin, L.V.: Brittle Fracture of Dental Amalgam, J Dent Res 44: 977, 1965.

2. Allen, F.C.; Asgar, K.; and Peyton, F.A.: Microstructure of Dental Amalgam, $J$ Dent Res 44: 1002-1012, 1965.

3. Younis, O.: Forces Needed to Initiate a Crack in Dental Amalgams, MS thesis, Uni- versity of Michigan, School of Dentistry, 1974.

4. GUenther, W.C.: Analysis of Variance, Englewood Cliffs, NJ: Prentice-Hall, Inc., 1964.

5. Asgar, K.: Behavior of Copper in Dispersed Amalgam Alloy, abstracted, IADR Program and Abstracts of Papers, No. 15, 1971.

6. MaHLer, D.B.: Microprobe Analysis of a Dispersant Amalgam, abstracted, IADR Program and Abstracts of Papers, No. 14, 1971.

7. Asgar, K.: Amalgam Alloy with a Single Composition with Behavior Similar to Dispersalloy, J Dent Res 53 (Special Issue): Abstract No. 23, 1974.

8. Fairhurst, C.W.: Crystallography of Dental Amalgam, PhD dissertation, Northwestern University, 1966.

9. Wing, G., and Ryge, G.: Setting Reactions of Spherical-Particle Amalgams, J Dent Res 44: 1325-1333, 1965. 